\title{
Shear Slip Instability Behavior of Rock Fractures under Prepeak Tiered Cyclic Shear Loading
}

\author{
Minglei Zhai, Haibo Bai $\mathbb{D}^{\mathrm{D}}$, and Luyuan Wu \\ State Key Laboratory of Geomechanics and Deep Underground Engineering, China University of Mining and Technology, \\ Xuzhou 221116, Jiangsu, China \\ Correspondence should be addressed to Haibo Bai; baihbcumt@126.com
}

Received 3 June 2020; Revised 18 September 2020; Accepted 12 October 2020; Published 22 October 2020

Academic Editor: Chunshun Zhang

Copyright ( 2020 Minglei Zhai et al. This is an open access article distributed under the Creative Commons Attribution License, which permits unrestricted use, distribution, and reproduction in any medium, provided the original work is properly cited.

In this paper, shear displacement properties of rock fractures were studied, and the energy evolution process was analyzed before sliding instability under complex shear loading paths. The artificial prefabrication method was used to simulate the natural rock fractures, which are difficult to obtain in the natural environment. The prepeak tiered cyclic loading tests under constant normal loading were performed on six rock specimens with fractures by rock direct shear apparatus (RDS-200). To obtain the stress difference of adjacent cycles, the direct shear test was conducted on the other six rock specimens with fractures before the prepeak tiered cyclic shear loading test. The variation trend of residual shear displacement (RSD) and the similarity of loading and unloading curves before slip instability were obtained by analyses of prepeak tiered cyclic shear loading test data. Energy evolution laws of rock fractures were analyzed with the consideration of the hysteresis characteristics, according to the hysteresis effect of shear displacement behind shear stress. This paper provides guidance for the study on shear instability of rock fractures under complex loading paths.

\section{Introduction}

Rock fractures have a controlling function in the stability of the rock slope with a planar failure surface $[1,2]$. The failure inside rock mass often occurs along the weak structural plane, and deformation and failure of rock projects are greatly affected by mechanical properties of the structural plane under the external loading [3-8]. Many engineering projects have shown that rock is not in a stable stress environment but is subjected to a cyclic loading-unloading stress environment [9-11]. Tiered cyclic loading is a common form acting on rock mass, such as periodical change of the reservoir level and reciprocating motion of the train [12-15]. The rough fluctuation of rock fractures is suffered from periodic wear and passivation, leading to the deterioration of its shear strength under cyclic shear loading. As a result, the dislocation and slippage of the rock mass are caused along with rock fractures, leading to the instability and failure of rock mass [3]. Thus, it is important to study the cumulative damage of rock fractures under tiered cyclic loading to evaluate the dynamic stability of rock mass accurately, and this problem is urgent to be solved.

In past decades, the influence of cyclic loading on the mechanical properties of rock fractures has been investigated by many scholars. In most experimental and theoretical studies on shear mechanical properties of rock fractures under cyclic shear loading, the constant shear rate is employed, and the peak value of shear strength of rock fracture is exceeded in each cyclic loading [16-21]. Li et al. [16] presented a constitutive model to predict the shear behavior of rock joints under cyclic loading, and the validation results show that the model can well predict the shear behavior of regularly shaped joints, but the accurate prediction for irregularly shaped joints depends on the quantitative description of joint surface roughness. Fathi et al. [17] made thirteen mortar replica specimens from natural unweathered granite joint and found that the steepest asperities that are facing the shear direction came into contact in shearing before peak in the monotonic test. The critical analyses of conventional calculations of parameters result in 
improved calculation methods with mechanistic reasoning for the ultimate application of the data to sophisticated numerical models with explicit or discrete rock mass structure [18]. Kou et al. [19] investigated in the laboratory the mechanical response of rock joints with multiscale triangular-shaped asperities, including primary and subordinate asperities, when subjected to prepeak cyclic shear loads and static constant normal loads (CNL). Liu et al. [20] investigated the shear mechanism of fatigue damage in rock joints with first-order and second-order triangular asperities under prepeak cyclic loading conditions and found that fatigue damage occurs at the second-order asperities in the upper and lower blocks within low number of cycles, but the fatigue cracks initiated with initiation angle of $90^{\circ}$ with respect to the first-order asperities in the upper and lower blocks coalesce with each other (or rock joints) within the high number of cycles. To better understand the shear mechanical behavior, the information value (IV) and the fractal theory (FT) models are employed to determine the shear failure regions of rock joints under the low effective normal stress conditions [21]. The previous research has shown that, during the periodical change of the reservoir level and reciprocating motion of the train, rock masses are affected in the form of tiered cyclic loading, and the failure of rock fractures caused by tiered shear loading was different from that by the shear loading state at a constant rate [22]. Compared with the shear test at the constant shear rate, the slip and dislocation caused by the prepeak tiered shear stress on the rock fracture are not obvious, because the prepeak tiered shear stress is smaller than the peak shear stress. Therefore, the obtained cumulative damage characteristics and mechanical properties of rock fractures under prepeak tiered shear load will be more consistent with the actual stress state.

The essence of deformation and failure of rock mass is the instability driven by energy $[15,23,24]$. The energy evolution process involves energy absorption, agglomeration, dissipation, release, transformation and transmission [1]. The internal nature of rock deformation and failure is reflected by the energy evolution mechanism [25]. Studies on the mechanical behavior of rock mass from the perspective of the energy have been conducted, and their results have been successfully applied to many fields, such as geological engineering [3]. Unfortunately, research on rock fractures under tiered cyclic shear loading is rarely studied from the perspective of the energy evolution mechanism. Therefore, such research should be performed. In addition, due to the difficult sampling and the complex surface of natural rock fractures, uniform specimens with high strength gypsum, cement mortar, and other similar materials are often used for shear test of rock fractures [19, 20]. However, there are differences between similar material models and natural rock owing to their different mineral compositions. Therefore, processed samples by natural rock should be used to reduce such differences.

In this paper, rock samples containing artificial fractures produced by self-made mold were experimentally studied under prepeak tiered cyclic shear loading. Shear displacement characteristics and energy evolution of rock fractures were analyzed based on the hysteresis characteristics. It is hoped that the results will provide reference meaning for the study on the instability of rock fractures.

\section{Experimental Setup}

2.1. Experimental Apparatus. RDS-200 rock mechanics shear test system produced by American GCTS Company was used in this experiment. Figure 1 shows the experimental instrument and simplified diagram of the test facility of this experimental system, respectively.

The system has high reliability and accuracy. The normal and shear loading are $100 \mathrm{kN}$ and $50 \mathrm{kN}$ controlled by an electrohydraulic servocontrol system, respectively; and the displacement and loading accuracy are $10^{-3} \mathrm{~mm}$ and $10^{-4} \mathrm{MPa}$, respectively. Besides, this system has advantages of easy operation and simple programming process. The whole test system is composed of normal and shear mechanism, in which control cylinders, load sensor, displacement sensor, load conduction arm, pin, pressure head, and base are included.

2.2. Preparation of Rock Fractures. The intact marble sample (a cylinder with a diameter of $50 \mathrm{~mm}$ and a height of $100 \mathrm{~mm}$ ) was placed in the self-made splitting grinding tool for the preparation of rock fracture, as shown in Figure 2. The tool was composed of upper and lower parts with the same shape and cylindrical grooves. Wedge-shape steel wire with the same arc degree was embedded in the middle of the groove and slightly protruded from the arc surface of the grooves. The section line in the middle of the rock sample was coincided with the wire, guaranteeing the application of uniform linear compression stress on the side surface of the specimen perpendicular to the axis. It can be seen from Figure 2 that, under the action of the press machine, the formed fractures are basically parallel to the upper and lower ends of the sample and approximate to the natural shape. Figure 2 shows the simplified diagram of the rock sample with fractures.

Take the case of TJ-2; the rock fractures formed by the fracturing action are shown in Figure 3. The mineral composition is mainly calcite, dolomite, and magnesite, according to the result of apparatus testing. It is gray with particle size of $0.2-0.5 \mathrm{~mm}$ and uniform texture. It can be seen from Figure 3 that the waviness of the rock fracture is well, which avoids the dispersion of test results caused by the difference of fracture morphology to a certain extent.

In the laboratory, the purchased dry nonshrinking, quick-setting cement grout was mixed with water and then with a stir bar was immediately used before pouring into a prepared steel shear ring, according to the same method in [26]. The influence of the cement deformation was negligible. Figure 4 shows the preparation steps of samples, including clamping samples, filling cement grout, and daubing plasticine around the fracture. The sample with fractures was coupled by the clamping tools so that it was suspended vertically inside the shear ring, and the fracture just appeared out the shear ring. As a result, from the pouring of cement 


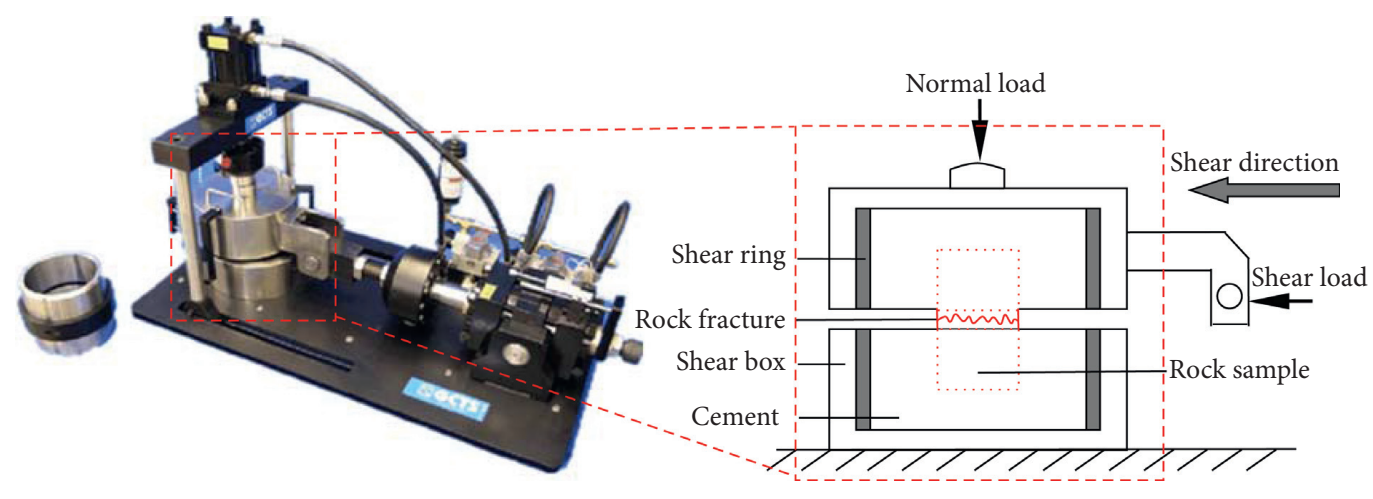

(a)

(b)

Figure 1: (a) RDS-200 rock mechanics shear test system. (b) Simplified diagram of the testing system [26].

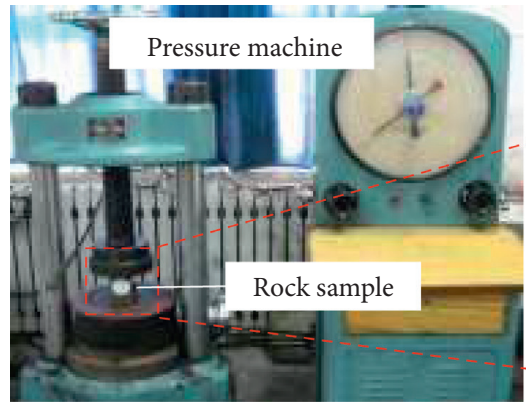

(a)

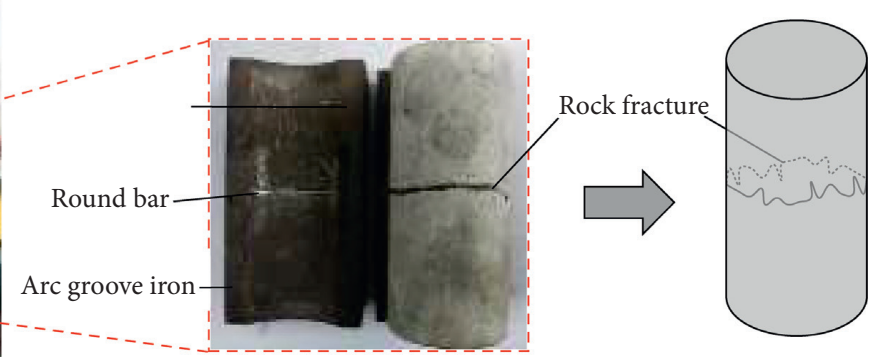

(b)

(c)

Figure 2: (a) The manufacture of rock fracture. (b) Rock fracture and splitting tool. (c) Simplified diagram.

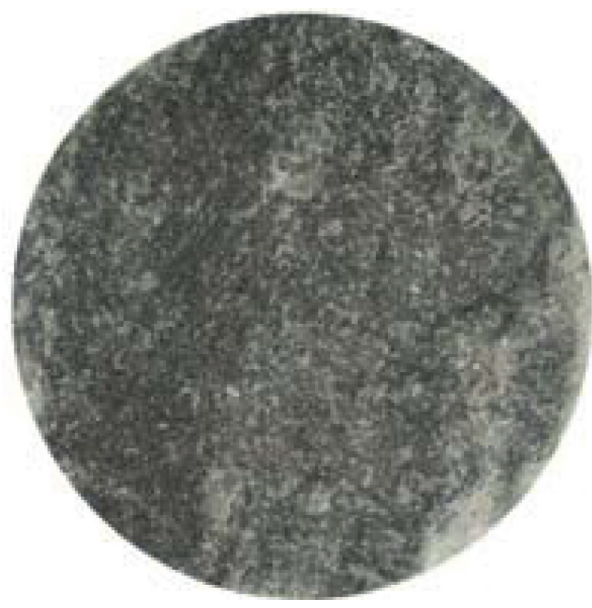

(a)

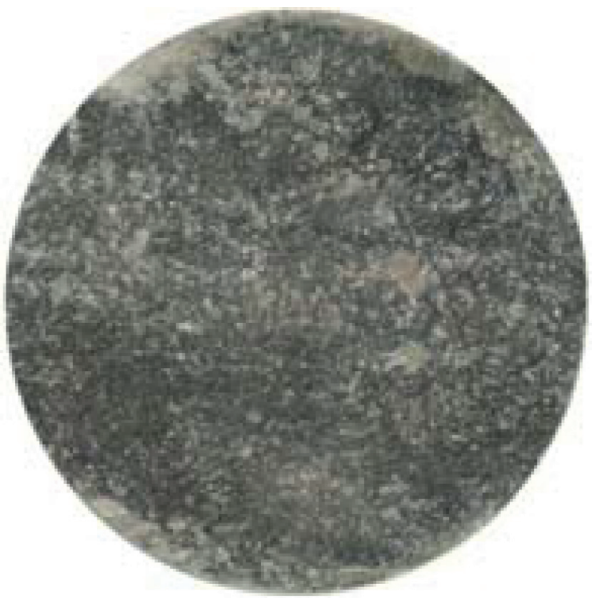

(b)

FIgURE 3: The morphology of rock fractures (take TJ-1 as an example). (a) Upper fracture surface. (b) Lower fracture surface.

grout into the surrounding space of the sample to the cured cement grout, a stable platform was provided for the sample by clamping tools. The rupture of the sample and the tested cement grout was not observed, indicating that the cement grout provided enough support to withstand normal loading without interfering with the test results. The test was conducted the daytime of summer to shorten the curing time of cement grout. When the surface was hard but warm from curing, a $0.5 \mathrm{~cm}$ thick plasticine layer was applied around the target shear zone manually. The plasticine, used to isolate fracture and cement grout, was negligible in the test because its stiffness and strength are lower than these of rock samples. The steel shear ring of the upper part was placed after the plasticine was completed. A black steel collar was tightened by hand to keep the sample aligned while the cement grout was solidified. A fully prepared direct shear sample is shown in Figure 4. Before placing the shear ring in the shear box, the collar was removed, and then the fracture 


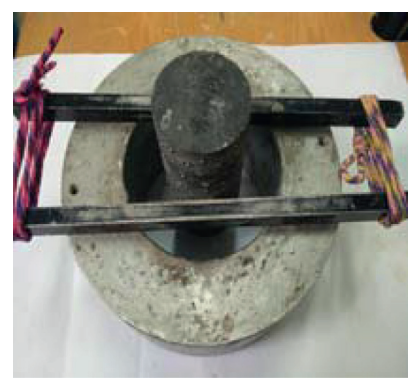

(a)

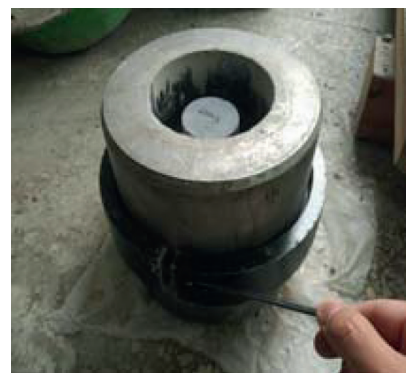

(e)

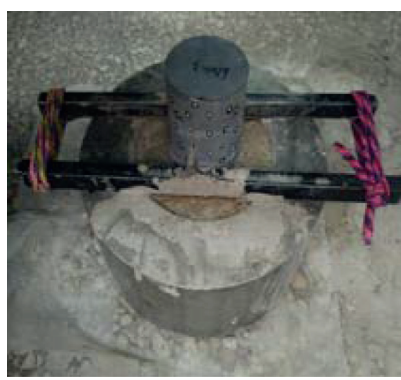

(b)

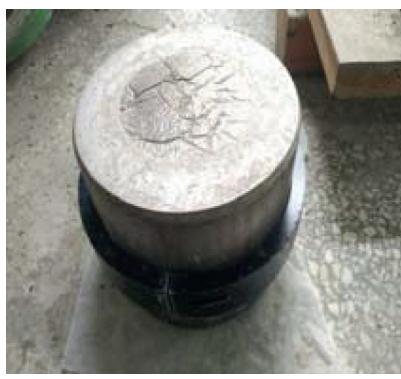

(f)

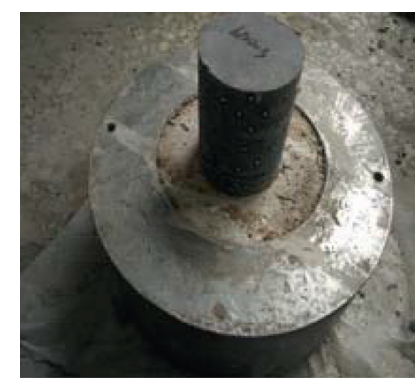

(c)

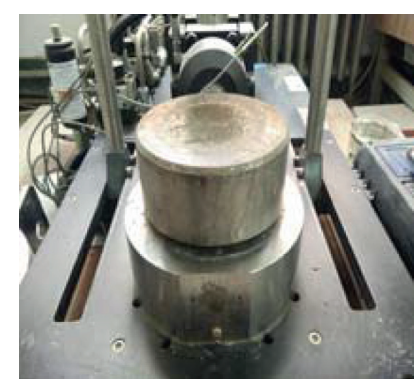

(g)

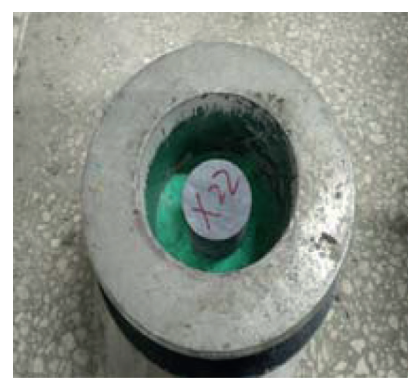

(d)

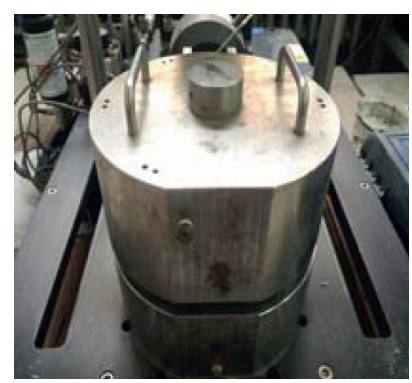

(h)

Figure 4: Shear sample preparation for interblock and intrablock sample. (a) Rock sample with fracture vertical suspension in the lower shear ring using clamping tools. (b) Pouring grout into the shear ring, and the fracture surface is higher than the end surface of the shear ring. (c) Completion of grout consolidation and removal of clamping tools. (d) $0.5 \mathrm{~cm}$ thick layer of rubber mud is formed onto grout surface. (e) Placing the upper shear ring and aligning and fixing the upper and lower shear rings. (f) Pouring grout into the upper shear ring, waiting for solidification. (g) Placing the shear ring in the lower shear box. (h) Covering the upper shear box for a shear test.

surface was the only contacting point in the middle of the sample (load-bearing). For the test, the sample was covered with the upper shear box that was coupled with the normal and shear loading actuators.

2.3. Testing Scheme. Twelve samples with rock fractures were prepared in this experiment. To achieve a certain cycle series in tiered cyclic loading experiment, six samples were used for direct shear test for the determination of the shear strength of fractures, providing a reference for the classification of shear stress in tiered cyclic shear loading test. The direct shear test showed that the average shear strength of the fractures was $3.461 \mathrm{MPa}$ when normal stress was 1.0 MPa (see Figure 5). According to the average shear strength of the rock fractures (3.461 MPa) and the enhanced damage effect significantly of tiered cyclic loading on the fracture, the maximum shear stress was set to an increment of $0.3 \mathrm{MPa}$ per cycle (TJ-1 to TJ-6).

The loading-unloading cycle path is shown in Figure 6. The normal stress was constantly applied to the target value of $1 \mathrm{MPa}$ at a rate of $0.02 \mathrm{MPa} / \mathrm{s}$ from $0 \mathrm{MPa}$. Then, shear stress was continuously loaded and unloaded at a speed of $0.005 \mathrm{MPa} / \mathrm{s}$ and $0.01 \mathrm{MPa} / \mathrm{s}$, respectively. Each specimen was designed to be loaded and unloaded ten times continuously, i.e., $\quad 0.0 \mathrm{MPa} \longrightarrow 0.3 \mathrm{MPa} \longrightarrow 0.0 \mathrm{MPa}$ $\longrightarrow 0.6 \mathrm{MPa} \longrightarrow 0.0 \mathrm{MPa} \longrightarrow 0.9 \mathrm{MPa} \longrightarrow 0.0 \mathrm{MPa}$ $\longrightarrow 1.2 \mathrm{MPa} \longrightarrow 0.0 \mathrm{MPa} \longrightarrow \ldots$, until shear slip instability occurred on the rock fractures obviously.

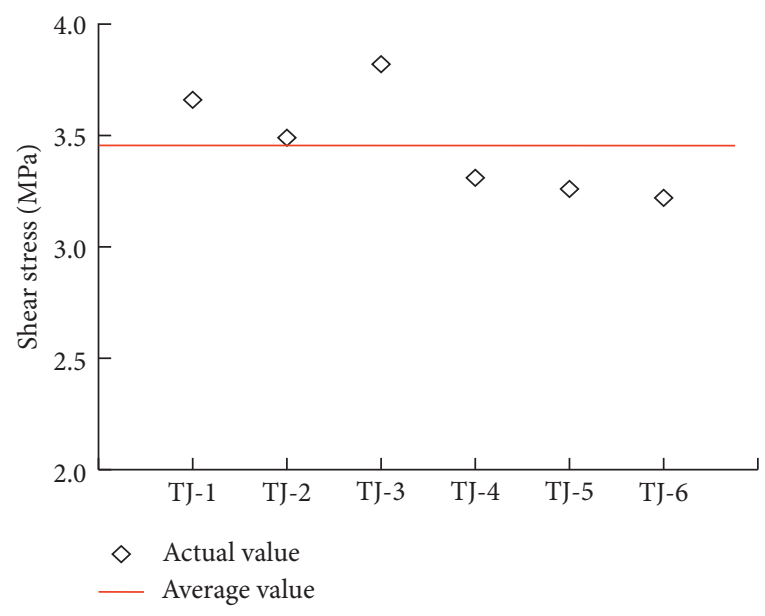

Figure 5: The direct shear strength and average value of rock fractures $(\sigma=1.0 \mathrm{MPa})$.

\section{Experimental Results and Analysis}

3.1. Analysis of Shear Deformation. Figure 7 shows shear stress-shear displacement $(T-\delta)$ curves of the six samples with rock fractures under prepeak tiered cyclic shear loading with constant normal stress $(\sigma=1.0 \mathrm{MPa})$. Although these $T$ $\delta$ curves are obtained from rock fractures with different morphology parameters, they have similar trends under prepeak tiered cyclic shear loading. The envelopes of $T-\delta$ curves and direct shear curves have the same characteristics [3], and the envelopes of $T-\delta$ curves can be roughly divided 


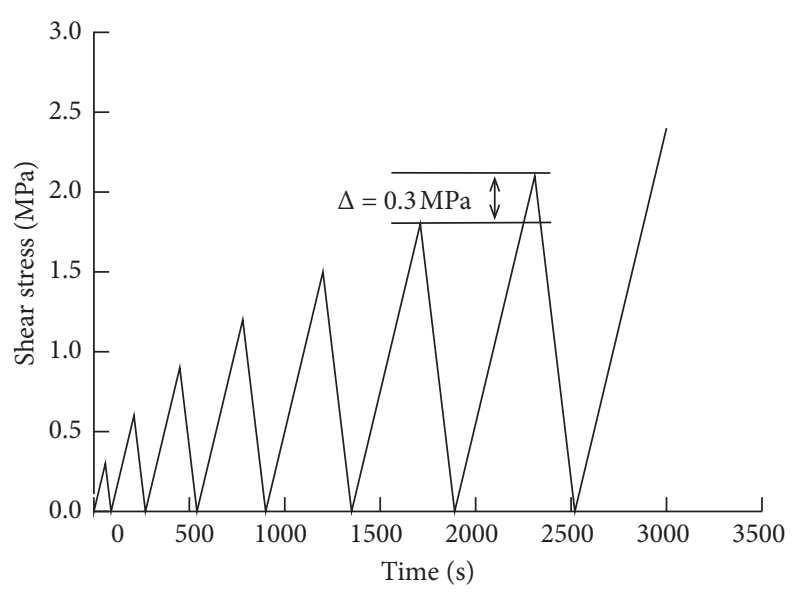

FIgURE 6: The tiered loading-unloading cycles for shear testing.

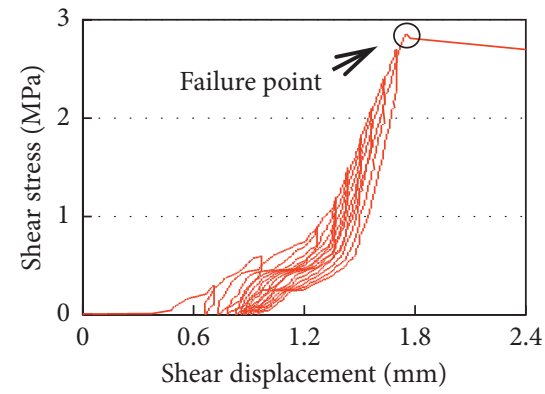

(a)

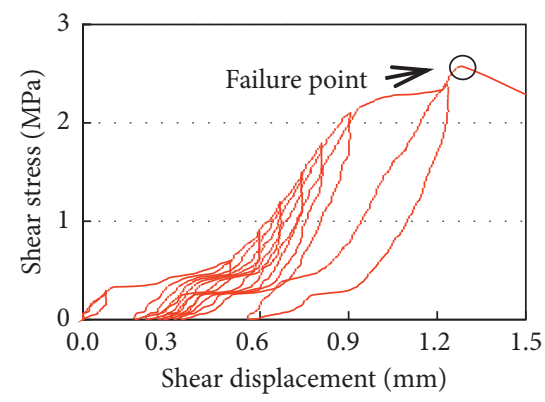

(d)

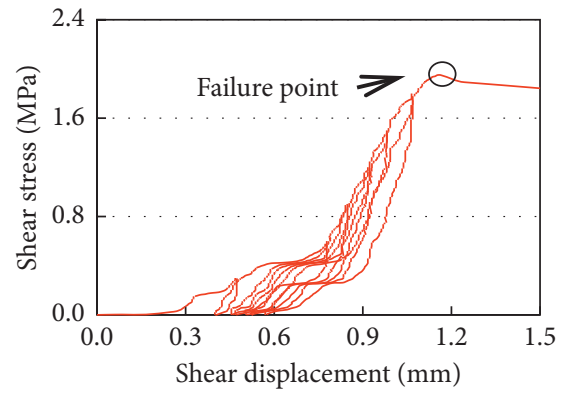

(b)

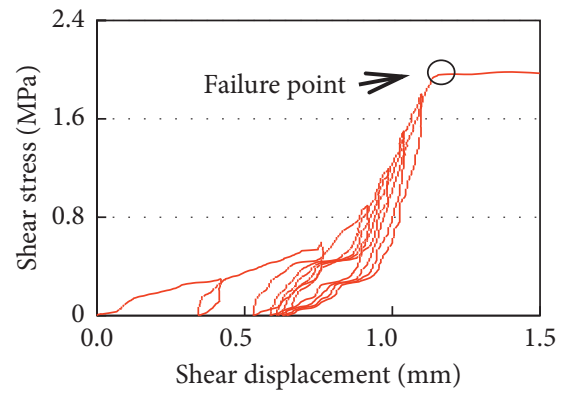

(e)

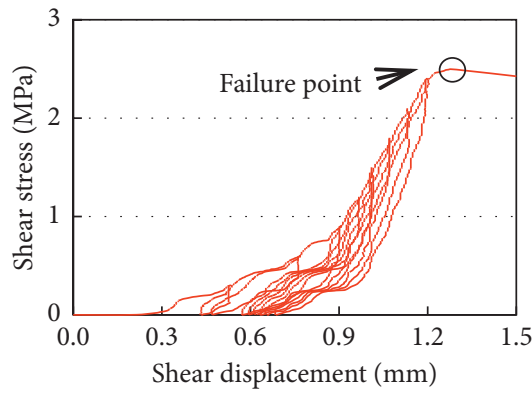

(c)

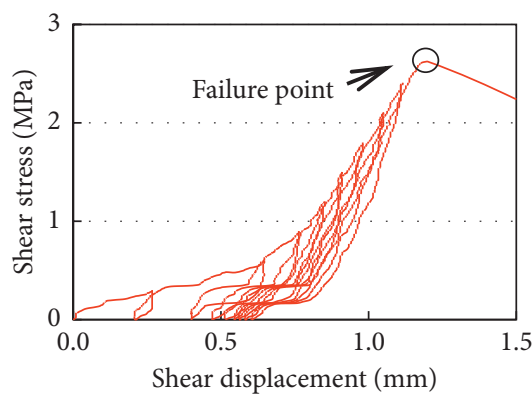

(f)

Figure 7: T- $\delta$ curves under tiered cyclic shear loading for (a)-(f): TJ-1-TJ-6.

into compaction stage, linear elastic stage, and shear slip instability stage through a model. The reloading $T-\delta$ curves continue to increase along the loading curve of the last cycle, which indicates that the rock fractures have memory functions under prepeak tiered cyclic shear loading. The effect of prepeak tiered cyclic shear loading has little influence on the shear deformation behavior of rock fractures. Shear strength of the six rock fractures under prepeak tiered cyclic shear loading is lower than the average direct shear strength due to the continuous damage caused by the cyclic shear loading.

As shown in Figure 8, $T-\delta$ curves for every loading and unloading stage of the six samples are plotted in accordance with the tiered series. Since the curves overlap with each other, their essential differences are difficult to be seen
(Figure 7). As presented in Figure 8, the loading and unloading curves deviate far from each other in the first cycle. The residual shear displacement (RSD) is defined as the $\delta$ of shear stress unloading to $0 \mathrm{MPa}$. And when the shear stress is unloaded to $0 \mathrm{MPa}$, a large RSD is observed and mainly caused by the coupling compaction. A curve similar to the shape of a "horn" is formed in the loading and unloading curves in the first cycle; and in the second cycle, a "bamboo" curve is formed. Besides, the loading and unloading curves are not coincident whereas they are gradually approached. All the unrecoverable RSD are analyzed after tiered loading and unloading, and RSD gradually increases with the cyclic loading and unloading (Figure 9). The relative residual shear displacement (RRSD) is defined as the difference between the adjacent RSD. It can be seen 


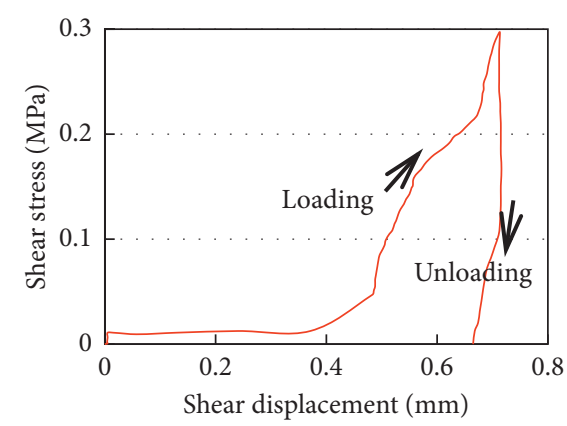

(a)

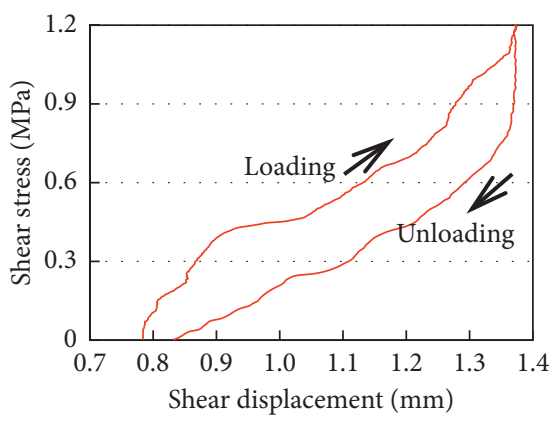

(d)

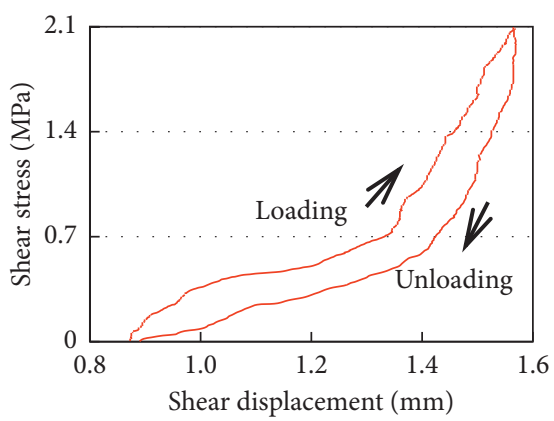

(g)

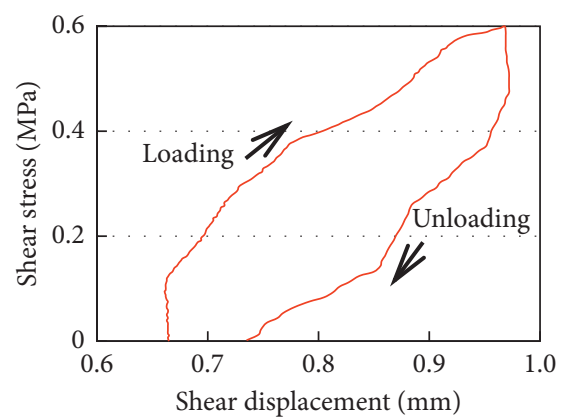

(b)

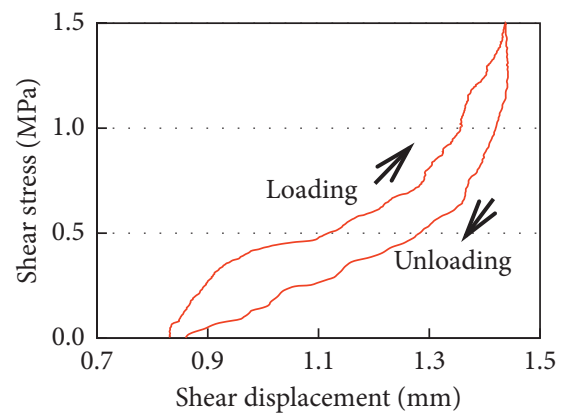

(e)

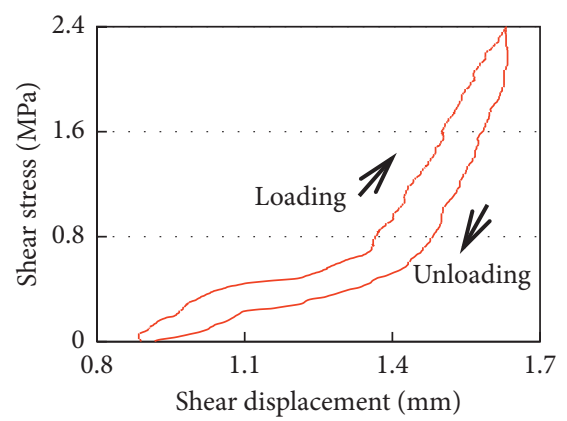

(h)

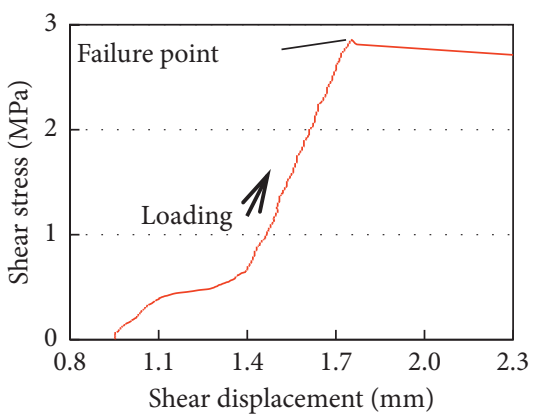

(j)

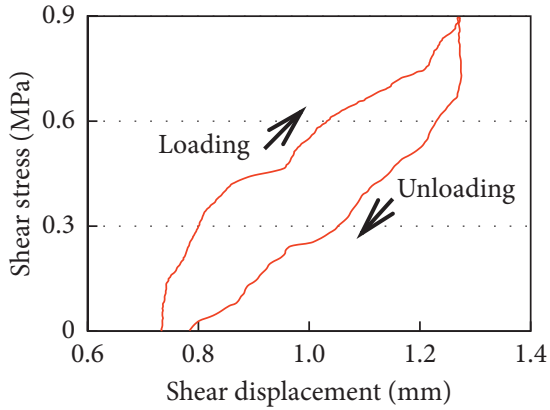

(c)

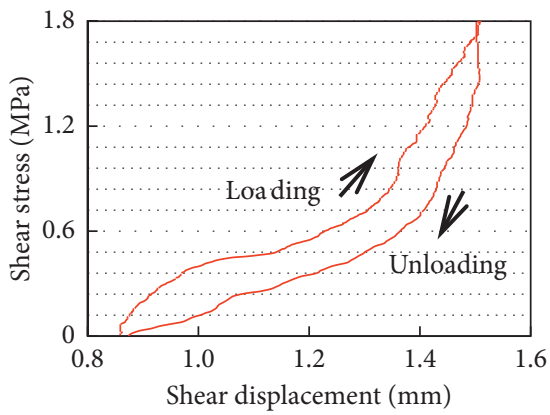

(f)

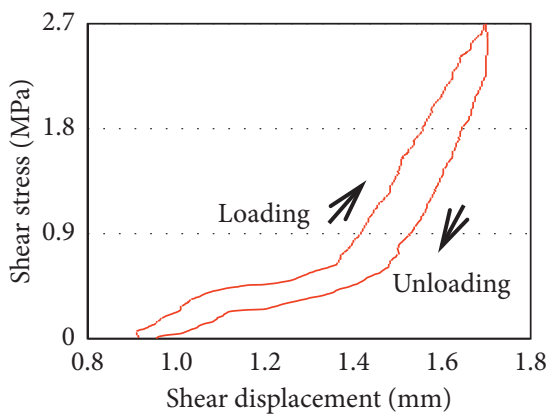

(i)

Figure 8: T- $\theta$ curves of TJ-1 at different cycles for (a)-(j): 1st-10th.

that RRSD is larger at the initial cycles and then decreases with the continued cycles (Figure 9) (the RSD is equal to the RRSD in the first cycle). The hysteresis effect of shear displacement lagging behind shear stress is gradually reduced and stabilized as the increase of the continued cycles.

Loading and unloading curves are basically the same in the two adjacent complete cycles before shear slip instability. However, when the shear stress $T$ reaches the loading limit required by the slip instability of the rock fractures, the sudden increase of shear displacement $\delta$ results in the shape changes of the same loading and unloading curves. The two extremely similar adjacent loading and unloading curves before failure can be used as a way to predict the burst of shear instability.

The morphology of rock fractures under prepeak tiered cyclic shear loading and direct shear stress are shown in 


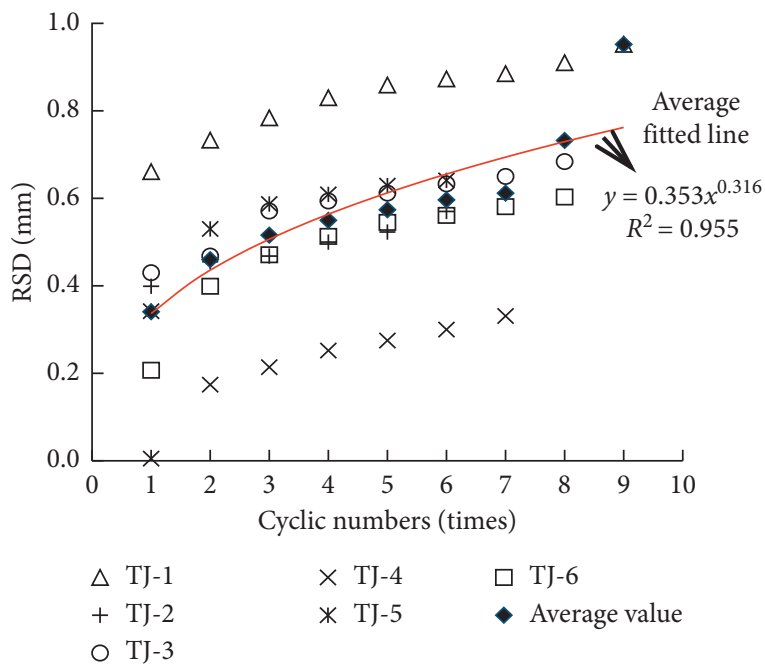

(a)
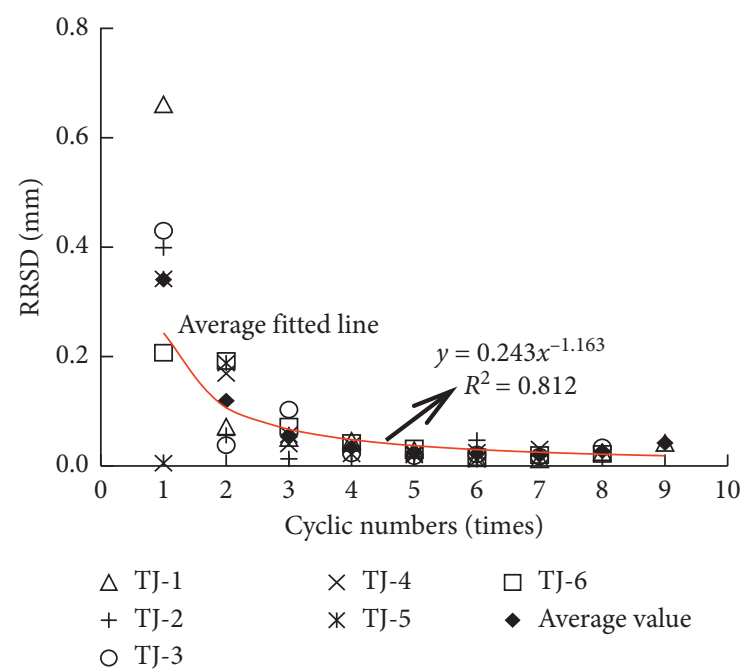

(b)

FIGURE 9: The shear displacement at different cycles numbers. (a) Residual shear displacement (RSD). (b) Relative residual shear displacement (RRSD).

Figures 10 and 11, respectively. It can be found that the fracture surface morphology under prepeak tiered cyclic shear loading was clearer, and local wear occurred. However, the fracture surface morphology under direct shear stress is not, which is covered by rock debris. The direct shear test was more serious to the rock fractures.

3.2. Shear Slip of $T-\delta$ Curves. It is seen from Figure 7 that when $T$ is loaded or unloaded to a certain level, $\delta$ increases or decreases rapidly. From the third stage, $\delta$ increases significantly $(0.351-0.448 \mathrm{~mm})$ during the loading stage, while the $T$ increases slightly $(0.427-0.481 \mathrm{MPa})$. During the unloading stage, $\delta$ and $T$ decrease significantly $(0.502-0.379 \mathrm{~mm})$ and decrease slightly $(0.292-0.253 \mathrm{MPa})$, respectively. The rapid increase of $\delta$ (shear slip) in the loading stage is different from the shear slip instability caused by the loading of the last cycle. The increasing $T$ can be sustained by fracture after a short slip, whereas the large displacement will be caused, resulting in a high possibility of the serious damage in engineering practice.

The above phenomenon can be explained as follows: the coupling fractures are in the state of static friction when the $T$ is low, and $\delta$ is mainly caused by defects of the fracture and a small elastic displacement of bump and convex body distributed randomly, that is, the compaction of coupling fracture. At this time, wear particles in the fracture are caused by the increasing $\delta$ and increase with the increasing $T$. With the increase of $T$, the fracture is in the alternated state of static friction and sliding friction. However, the effect of static friction on the fracture surface is weakened by wear particles, and the overall sliding rate increases rapidly. With increasing $T, T-\delta$ has a nearly linear increase, and fractures change from static friction to sliding friction. Then the effect of wear particles on shear dislocation of bump and convex body and shear sliding rate is weakened. Therefore, the main cause of fluctuation of $T-\delta$ curves is the change of friction state of the rock fractures.
3.3. Energy Analysis. The deformation and failure of rock samples are accompanied by energy conversion $[27,28]$. The rock damage process is essentially energy dissipation [29-31]. In the tiered cyclic loading tests of complete coal and rock samples, the traditional view holds that the deformation will immediately increase or decrease with the loading or unloading progress, respectively. As shown in Figure 12, $a$ and $b$ are the primary unloading point and the secondary loading point, respectively. In other words, the shear displacement decreases and increases at points $a$ and $b$, respectively. But this is not the case in this experiment. As shown in Figure $12\left(a^{\prime}-b^{\prime}, c^{\prime}-d^{\prime}\right)$, the shear displacement did not decrease or increase immediately with the change of shear stress. However, due to inertial forces, there is a small increase or decrease in displacement. Here, sample TJ-1 in the eighth cycle is taken as an example. As shown in Figure 13, the errors are caused obviously in the calculation of energy. Therefore, the energy calculation method considering the effect of shear displacement lagging behind shear stress is closer to the real situation.

For Figure 12(b), the following details can be obtained. $\delta$ increases with the increasing $T$, until $T$ reaches the maximum value $T_{1}$ at the first level $\left(o-a^{\prime}\right)$. Starting at the point $a^{\prime}, \delta$ increases slightly with the decreasing $T\left(a^{\prime}-b^{\prime}\right)$. This is because the fracture has been damaged under the shearing action and its bearing capacity has been reduced, and then the shear stress corresponding to the original loading cannot be sustained. Under this stress, the displacement and the deformation of the specimen will increase until its bearing capacity is equal to $T\left(b^{\prime}\right)$. For metal specimens with no damage and full elasticity, $\delta$ decreases immediately with the decreasing $T$ after unloading. At point $c^{\prime}, \delta$ continues to decrease with the increasing $T$, while the increased $T$ is not enough to overcome the inertia or make fracture move forward $\left(c^{\prime}-d^{\prime}\right)$. As $T$ reaches a certain value, the inertia effect is overcome, and then $\delta$ increases with the increasing $T\left(d^{\prime}-f^{\prime}\right)$. For simplicity, the same variation in the next few cycles is not repeated. 


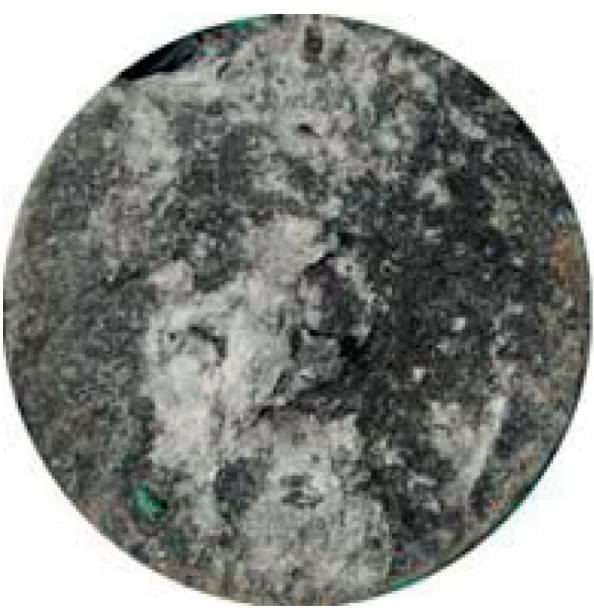

(a)

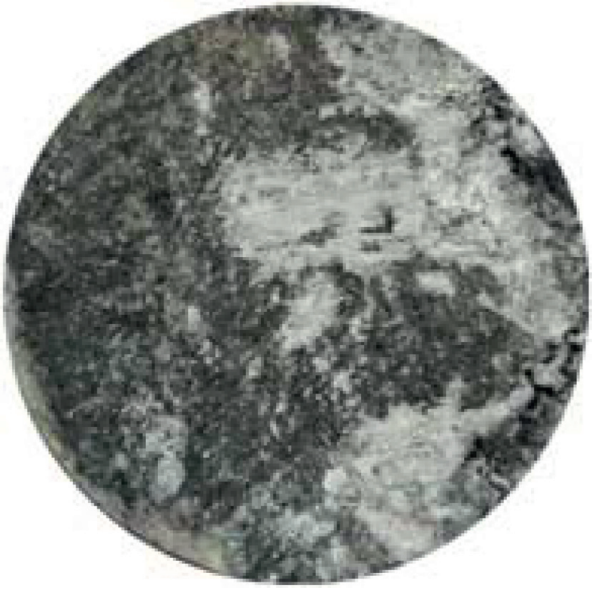

(b)

FIGURE 10: Under prepeak tiered cyclic shear loading. (a) Upper fracture surface. (b) Lower fracture surface.

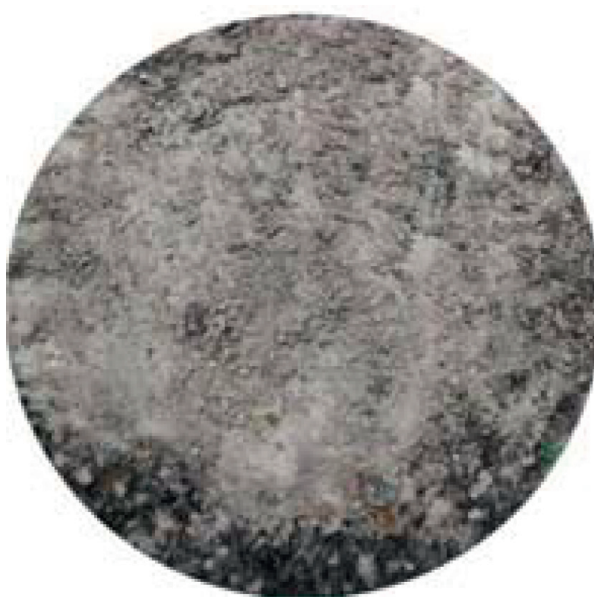

(a)

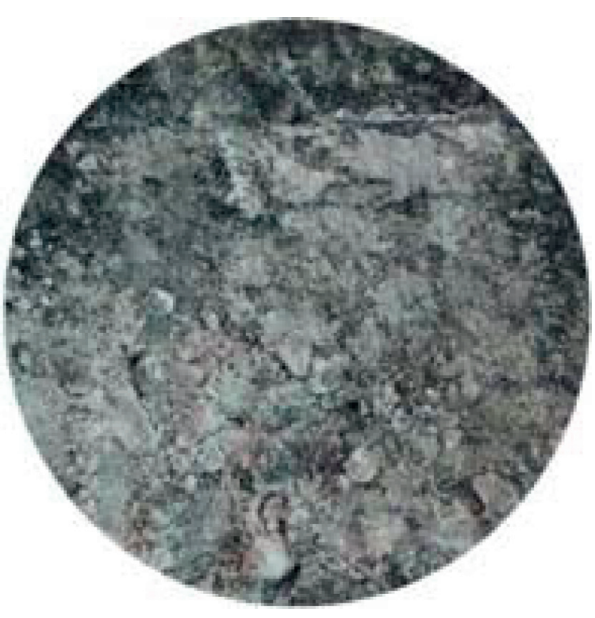

(b)

FIGURE 11: Under direct shear stress. (a) Upper fracture surface. (b) Lower fracture surface.

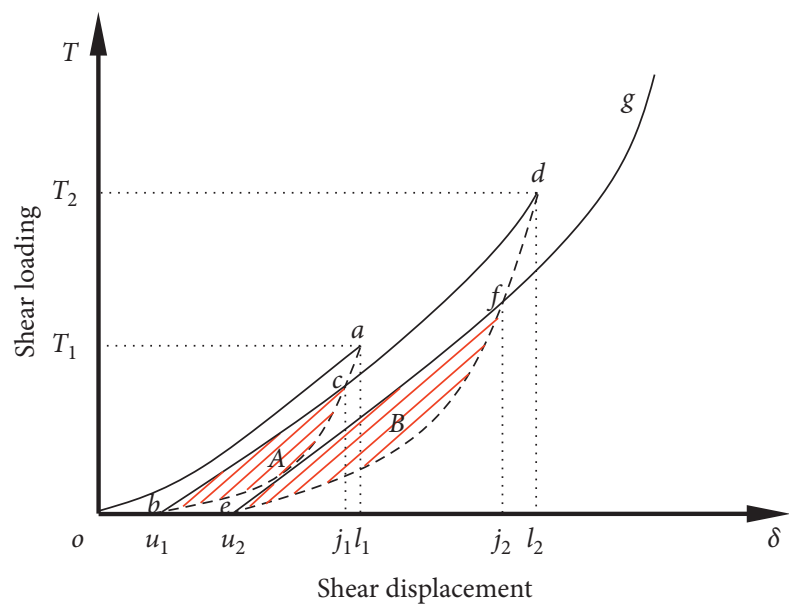

- Loading curves

--- Unloading curves

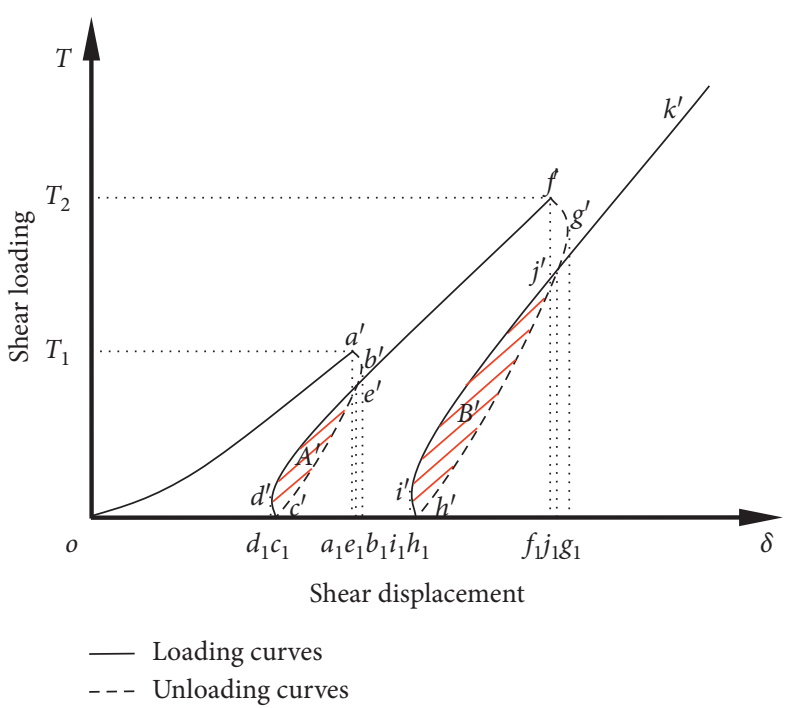

(b)

Figure 12: T- $\delta$ curves. (a) Ideal. (b) Actual. 


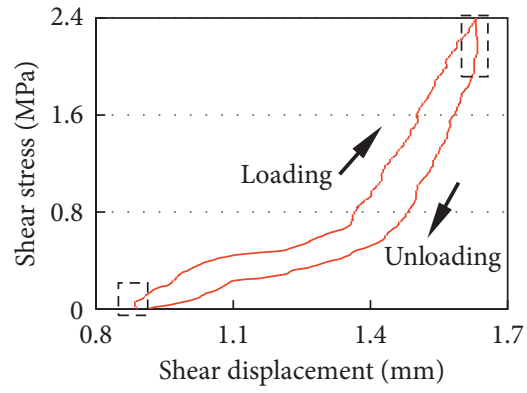

(a)

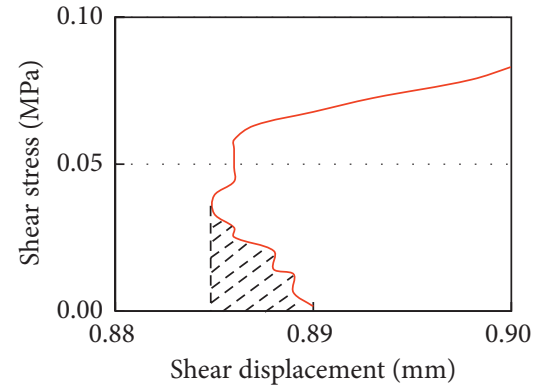

(b)

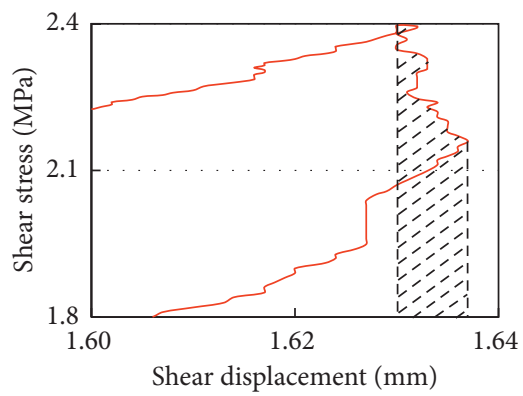

(c)

Figure 13: $T$ - $\delta$ curves for sample TJ-1 at the 8th cycle. (a) Curve of the full loading-unloading process. (b) Enlarged curve around loading point. (c) Enlarged curve around unloading point.

The energy analysis of the above description is as follows. $T$ and $\delta$ increase in the loading stage of the first cycle, as shown in Figure 12(b) $\left(o-a^{\prime}\right)$ and $T$ has a positive work on rock fracture. For $a^{\prime}-b^{\prime}, T$ also has a positive work, since the increasing $\delta$ in spite of $T$ is reduced. However, $T$ has a negative work in $b^{\prime}-c^{\prime}$; that is, $\delta$ decreases and the rock fracture releases energy outward; in $c^{\prime}-d^{\prime}, T$ increases, but $\delta$ decreases; thus $T$ has a negative work. For simplicity, the same energy analysis for each shear cycle is not repeated.

From the above analysis, the total positive and negative work of shear direction on fracture is obtained, according to $T-\delta$ curves obtained in each loading and unloading cycle (after the conversion between stress and load). In the process of rock fracture shearing, the change of normal displacement must be accompanied; that is, there are dilatation and contraction, and the normal load also does work on the fracture. When dilatancy exists, the normal load does negative work to the fracture. When shear shrinkage exists, the normal load does positive work on the fracture. The work done by the normal load can be calculated by considering the initial and final values of the normal displacement in each shear stage, since the normal load remains constant throughout the shear stage.

The tangential inputted energy $\left(U_{s}\right)$ during the first shear loading process is transformed into the tangential elastic energy $\left(U_{\text {se }}\right)$ stored in fracture, and the tangential dissipated energy $\left(U_{\mathrm{sd}}\right)$ is released during the damage process. In the tiered cyclic shear loading test, $U_{\mathrm{s}}$ is represented by the complete $T$ - $\delta$ curves and the shear deformation axis in each cycle, and $U_{\text {se }}$ is calculated by the shear unloading curve and the shear deformation axis in each cycle. $U_{\text {sd }}$ in each cycle is computed by the relationship $\left(U_{\mathrm{sd}}=U_{\mathrm{s}}-U_{\mathrm{se}}\right)$. The formulas for calculating the $U_{s}, U_{\mathrm{se}}$, and $U_{\mathrm{sd}}$ are as follows:

$$
\begin{aligned}
U_{s} & =\int_{o}^{a_{1}} f_{1}(\delta) \mathrm{d} \delta+\int_{a_{1}}^{b_{1}} g_{1}(\delta) \mathrm{d} \delta, \\
U_{\mathrm{se}} & =\int_{b_{1}}^{c_{1}} h_{1}(\delta) \mathrm{d} \delta, \\
U_{\mathrm{sd}} & =\int_{o}^{a_{1}} f_{1}(\delta) \mathrm{d} \delta+\int_{a_{1}}^{b_{1}} g_{1}(\delta) \mathrm{d} \delta-\int_{b_{1}}^{c_{1}} h_{1}(\delta) \mathrm{d} \delta,
\end{aligned}
$$

where $f_{1}(\delta), g_{1}(\delta)$, and $h_{1}(\delta)$ are the curve fitting equations of $o-a^{\prime}, a^{\prime}-b^{\prime}$, and $c^{\prime}-d^{\prime}$, respectively.

The total inputted energy $(U)$ and the total elastic energy $\left(U_{\mathrm{e}}\right)$ of the external load during each loading cycle can be obtained by considering the normal loading in the calculation interval. The total dissipative energy $\left(U_{\mathrm{d}}\right)$ can be expressed in $\left(U_{\mathrm{d}}=U-U_{\mathrm{e}}\right)$. The formulas for calculating the $U, U_{\mathrm{e}}$, and $U_{\mathrm{d}}$ are as follows:

$$
\begin{aligned}
U & =U_{\mathrm{s}}+T \cdot S^{\prime} \cdot \Delta_{o}^{c}, \\
U_{\mathrm{e}} & =U_{\mathrm{se}}+T \cdot S^{\prime} \cdot \Delta_{b}^{c}, \\
U_{\mathrm{d}} & =U_{\mathrm{sd}}+T \cdot S^{\prime} \cdot\left(\Delta_{o}^{c}-\Delta_{b}^{c}\right),
\end{aligned}
$$

where $S^{\prime}$ is the contact area of coupling rock fractures and $\Delta$ is the normal displacement.

Figure 14 shows the changes in $U, U_{\mathrm{e}}$, and $U_{\mathrm{d}}$ with the increasing cyclic numbers. Generally, $U$ and $U_{\mathrm{e}}$ have a nearly linear increase with the increasing cyclic number, and there is a significant drop in the $3 \mathrm{rd}$ cycle of $U$. $U_{\mathrm{d}}$ reaches the peak 


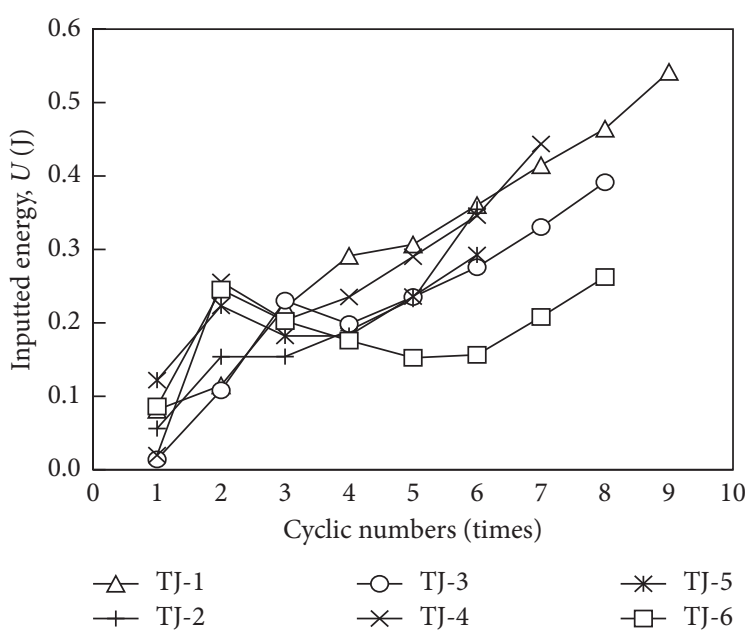

(a)

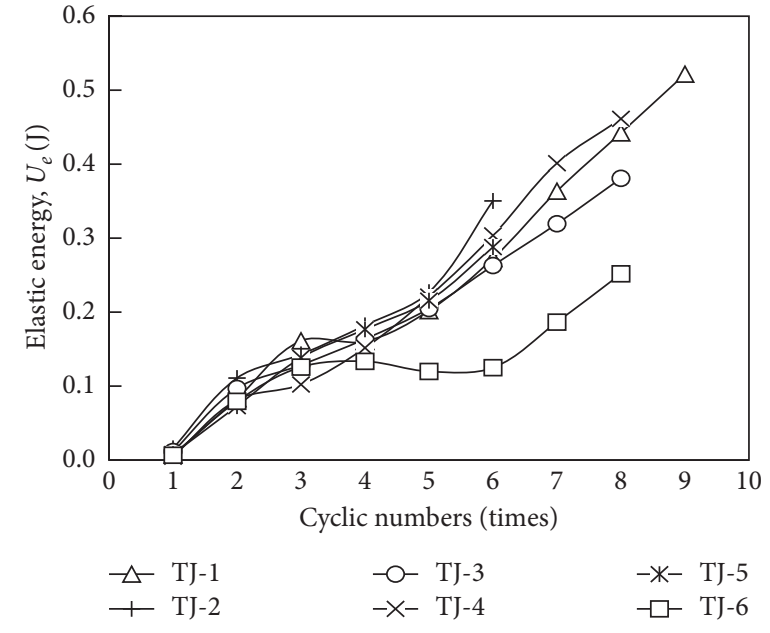

(b)

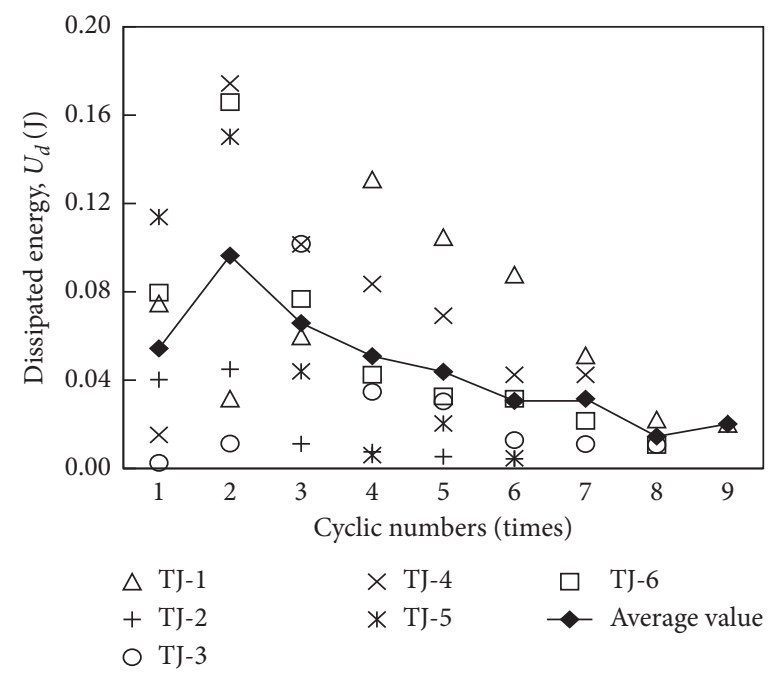

(c)

FIgURE 14: Energy evolution with tiered cyclic numbers. (a) Inputted energy, $U$. (b) Elastic energy, $U_{\mathrm{e}}$ (c) Dissipated energy, $U_{\mathrm{d}}$.

value in the 2nd cycle and then decreases gradually with the increasing cycle number, and the rate decreases gradually.

The above test results show that $U$ and $U_{\mathrm{d}}$ decrease significantly in the 3 rd cycle. This is because the concave and convex bodies on the rock fracture are compacted in the 1st and 2nd cycles, and an amount of inputted energy from the outside is consumed by a small amount of low-strength bumps. Shear slip of fracture is caused by damaged particles formed by the low-strength bulges, which weakens the friction of coupling fracture. Frictional hindrances are weakened by broken particles in the 3rd cycle, the convex deformation or destruction of rock fracture is less, and the inputted energy is mostly stored in the crack in the form of elastic energy. The deformable space decreases gradually, and $U_{\mathrm{d}}$ decreases with the increasing cyclic number due to the densification of fracture since the 3 rd cycle.

\section{Conclusions}

In this study, rock samples with artificially prefabricated fractures were experimentally investigated by RDS-200 servocontrolled rock direct shear experimental apparatus. Displacement characteristics and energy evolution were measured under prepeak tiered cyclic shear loading at a constant normal loading. The results are drawn as follows.

(1) The envelopes of $T-\delta$ curves under tiered cyclic shear loading are similar to those obtained in the direct shear test and can be divided into the compaction stage, linear elastic stage, and shear slip instability stage. Generally, the RSD and RRSD are affected by cyclic numbers; RSD increases with the increase of cyclic numbers, while RRSD increases with the increase of cyclic numbers. The two extremely similar 
adjacent loading and unloading curves before failure can be used as a way to predict the burst of shear instability.

(2) When the shear stress is loaded or unloaded to a certain stress level (in this paper, the third stress level), $\delta$ increases or decreases rapidly, while the sudden instability of the rock fracture cannot be caused. The change of friction and sliding state of rock fracture is the main reason for the fluctuation of $T-\delta$ curves.

(3) Considering the hysteresis effect of shear displacement behind shear stress, the method is closer to the actual value. Generally, $U$ and $U_{\mathrm{e}}$ increase with the increasing cyclic number, and $U$ decreases significantly in the 3 rd cycle. $U_{\mathrm{d}}$ reaches the peak value in the 2nd cycle and then decreases gradually in the form of decreasing rate.

This study contributes to the understanding of the shear instability of rock fractures under the condition of prepeak tiered cyclic shear loading with constant normal loading. Further studies both in tiered cyclic shear tests and in theory are necessary to be performed to comprehensively understand the cycle load mechanical behavior of rock fractures.

\section{Data Availability}

The data used to support the findings of this study are included within the article.

\section{Conflicts of Interest}

The authors declare that there are no conflicts of interest regarding the publication of this paper.

\section{Acknowledgments}

This work was supported by the Future Scientists Program of Double First Rate of China University of Mining and Technology under Grant no. 2019WLKXJ076.

\section{References}

[1] Y. F. Ge, H. M. Tang, L. Q. Wang et al., "Strain energy evolution of penetrative rock joints under shear loading," Chinese Journal of Rock Mechanics and Engineering, vol. 35, no. 6, pp. 1111-1121, 2016.

[2] S. Y. Song, Q. Xu, J. P. Chen et al., "Engineering classification of jointed rock mass based on connectional expectation: a case study for Songta dam site, China," Advances in Civil Engineering, vol. 2020, Article ID 3581963, 15 pages, 2020.

[3] M. L. Zhai, B. H. Guo, B. Y. Li et al., "Energy and deformation characteristics of rock joints under multi-stage shear loadingcreep-unloading conditions," Rock and Soil Mechanics, vol. 39, no. 8, pp. 2865-2872, 2018.

[4] Z. C. Tang, Q. Z. Zhang, J. Peng, and Y. Y. Jiao, "Experimental study on the water-weakening shear behaviors of sandstone joints collected from the middle region of Yunnan province, P. R. China," Engineering Geology, vol. 258, Article ID 105161, 2019.
[5] F. Meng, L. N. Y. Wong, H. Zhou, and Z. Wang, "Comparative study on dynamic shear behavior and failure mechanism of two types of granite joint," Engineering Geology, vol. 245, pp. 356-369, 2018.

[6] B. H. Guo, C. L. Wang, L. Wang, Y. Chen, and T. Cheng, “A modified cubic law for rough-walled marble fracture by embedding peak density," Advances in Civil Engineering, vol. 2020, Article ID 9198356, 10 pages, 2020.

[7] X. Ding, X. C. Xiao, X. F. Lv, D. Wu, and Y. Pan, "Analysis of similarities and differences between acoustic emission and charge signal based on fractal characteristics of coal fracture," Advances in Civil Engineering, vol. 2020, Article ID 8745039, 12 pages, 2020.

[8] L. Y. Wu, H. B. Bai, C. Yuan, C. Xu, and Y. Du, "A water-rock coupled model for fault water inrush: a case study in Xiaochang coal mine, China," Advances in Civil Engineering, vol. 2019, Article ID 9343917, 12 pages, 2019.

[9] R. D. Peng, Y. Ju, F. Gao et al., "Energy analysis on damage of coal under cyclical triaxial loading and unloading conditions," Journal of China Coal Society, vol. 39, no. 2, pp. 245-252, 2014.

[10] S. C. Xu, X. T. Feng, and B. R. Chen, "Experimental study of skarn under uniaxial cyclic loading and unloading test and acoustic emission characteristics," Rock and Soil Mechanics, vol. 30, no. 10, pp. 2929-2934, 2009.

[11] D. Li, Z. Sun, T. Xie, X. Li, and P. G. Ranjith, "Energy evolution characteristics of hard rock during triaxial failure with different loading and unloading paths," Engineering Geology, vol. 228, pp. 270-281, 2017.

[12] J. Wang, W. D. Song, S. Cao et al., "Mechanical properties and failure modes of stratified backfill under triaxial cyclic loading and unloading," International Journal of Mining Science and Technology, vol. 50, pp. 751-760, 2018.

[13] T. Li, X. Pei, D. Wang, R. Huang, and H. Tang, "Nonlinear behavior and damage model for fractured rock under cyclic loading based on energy dissipation principle," Engineering Fracture Mechanics, vol. 206, pp. 330-341, 2019.

[14] C. Jiang, M. Duan, G. Yin et al., "Experimental study on seepage properties, AE characteristics and energy dissipation of coal under tiered cyclic loading," Engineering Geology, vol. 221, pp. 114-123, 2017.

[15] F. Pei, H. G. Ji, and T. Z. Zhang, "Energy evolution and mechanical features of granite subjected to triaxial loadingunloading cycles," Advances in Civil Engineering, vol. 2019, Article ID 9871424, 11 pages, 2019.

[16] Y. Li, W. Wu, C. A. Tang, and B. Liu, "Predicting the shear characteristics of rock joints with asperity degradation and debris backfilling under cyclic loading conditions," International Journal of Rock Mechanics and Mining Sciences, vol. 120, no. 2, pp. 108-118, 2019.

[17] A. Fathi, Z. Moradian, P. Rivard, and G. Ballivy, "Shear mechanism of rock joints under pre-peak cyclic loading condition," International Journal of Rock Mechanics and Mining Sciences, vol. 83, pp. 197-210, 2016.

[18] J. J. Day, M. S. Diederichs, and D. J. Hutchinson, "New direct shear testing protocols and analyses for fractures and healed intrablock rockmass discontinuities," Engineering Geology, vol. 229, pp. 53-72, 2017.

[19] M. Kou, X. Liu, S. Tang, and Y. Wang, "Experimental study of the prepeak cyclic shear mechanical behaviors of artificial rock joints with multiscale asperities," Soil Dynamics and Earthquake Engineering, vol. 120, pp. 58-74, 2019.

[20] X. R. Liu, M. M. Kou, Y. M. Lu, and Y. Q. Liu, "An experimental investigation on the shear mechanism of fatigue damage in rock joints under pre-peak cyclic loading 
condition," International Journal of Fatigue, vol. 106, pp. 175-184, 2018.

[21] Y. F. Ge, Z. G. Xie, H. M. Tang et al., "Determination of shear failure regions of rock joints based on point clouds and image segmentation," Engineering Geology, vol. 260, pp. 1-11, 2019.

[22] L. F. Fan and L. N. Y. Wong, "Stress wave transmission across a filled joint with different loading/unloading behavior," International Journal of Rock Mechanics and Mining Sciences, vol. 60, pp. 227-234, 2013.

[23] H. P. Xie, Y. Ju, and L. Y. Li, "Criteria for strength and structural failure of rocks based on energy dissipation and energy release principles," Chinese Journal of Rock Mechanics and Engineering, vol. 24, no. 17, pp. 3003-3010, 2005.

[24] H. Xie, L. Li, R. Peng, and Y. Ju, "Energy analysis and criteria for structural failure of rocks," Journal of Rock Mechanics and Geotechnical Engineering, vol. 1, no. 1, pp. 11-20, 2009.

[25] Z. Song, T. Frühwirt, and H. Konietzky, "Characteristics of dissipated energy of concrete subjected to cyclic loading," Construction and Building Materials, vol. 168, pp. 47-60, 2018.

[26] H. Dong, B. Guo, Y. Li, K. Si, and L. Wang, "Empirical formula of shear strength of rock fractures based on 3D morphology parameters," Geotechnical and Geological Engineering, vol. 35, no. 3, pp. 1169-1183, 2017.

[27] F. N. Jin, M. R. Jiang, and X. L. Gao, "Defining damage variable based on energy dissipation," Chinese Journal of Rock Mechanics and Engineering, vol. 23, no. 12, pp. 1976-1980, 2004.

[28] D. Song, E. Wang, and J. Liu, "Relationship between EMR and dissipated energy of coal rock mass during cyclic loading process," Safety Science, vol. 50, no. 4, pp. 751-760, 2012.

[29] Z. Song, H. Konietzky, and T. Frühwirt, "Hysteresis energybased failure indicators for concrete and brittle rocks under the condition of fatigue loading," International Journal of Fatigue, vol. 114, pp. 298-310, 2018.

[30] X. S. Liu, J. G. Ning, Y. L. Tan, and Q. H. Gu, "Damage constitutive model based on energy dissipation for intact rock subjected to cyclic loading," International Journal of Rock Mechanics and Mining Sciences, vol. 85, pp. 27-32, 2016.

[31] T. L. Han, J. P. Shi, and Y. S. Chen, "Mechanical characteristics and failure characteristics of jointed rock under axial unloading and radial unloading," Advances in Civil Engineering, vol. 2020, Article ID 8812621, 15 pages, 2020. 